\title{
Assessing Households' Food Waste in Rural Yogyakarta
}

\author{
Sugiyarto ${ }^{*}$ \\ Department of Agricultural Socioeconomics, Faculty of Agriculture, Universitas Gadjah Mada, \\ Indonesia
}

\begin{abstract}
As consumers have been widely recognized as one of the largest driving forces in food waste, then knowledge about households' food consumption related to food waste behaviour is essential to understand. This study aims to identify the level of food waste based on the food categories and quantify the amount of food waste generated by rural households, particularly rice. Data were collected using a questionnaire conducted on a sample of 122 households which were selected randomly from 3 rural areas in Sleman and Bantul regencies. The first finding indicates rice and vegetables as the predominant types of food being wasted by households. The second finding ( 133 gr per household per day) provides a measure of the average amount of waste associated with the consumption of rice as households' staple food. This study gives further insights linked with the households' food consumption and the amount of food waste generated, which have previously been rarely studied, especially in rural areas.
\end{abstract}

\section{Introduction}

More population means more food to be provided. Demand for food is rising fast and will continue to grow due to rapid population growth. According to the UN Report, by 2050, the world population is estimated to reach about 9.7 billion people [1]. Indonesia as a developing country and the largest economy in South East Asia is predicted that there will be more than 305.6 million citizens by 2035 [2]. Ascending demand for food, primarily because of the fast population growth and diet changes, has imposed increasing pressure on food production.

Food waste becomes an important issue in the world as the challenge to feed the global population is rising. It is estimated that the world will need 60 percent additional food than what is currently produced to feed the projected world population by 2050 [3], while on another side there is about one-third of the world's edible food is lost and discarded per year [4]. It was recently reported that 1.3 billion tonnes of the world's food were wasted annually, with an associated cost of USD 750 billion [5]. From an economic point of view, looking at a more detailed number in several regions, it has been estimated that annually: Australians waste food worth USD 5.2 billion, Canadians waste USD 27 billion of food [6], meanwhile in the US, losses at the consumer level estimated around two-third of USD 133

\footnotetext{
${ }^{*}$ Corresponding author: sugiyarto.pnugm@ugm.ac.id
} 
billion or USD 371 per capita [7,8], in the UK, food waste costs GBP 680 per household [9] and approximately GBP 454 in the case of an average Italian family [10]. Previous data show that food waste is expensive, and reducing food waste will benefit the world and countries by saving huge amounts of money and adding food supply.

Table 1. Estimated food waste from previous studies

\begin{tabular}{|l|l|l|}
\hline Country/World & Estimated Food Waste & Reference \\
\hline World & Almost 50\% of Total Prod & {$[4]$} \\
& $33 \%$ of Total Prod & {$[4]$} \\
& More than $25 \%$ of Total Prod & {$[11]$} \\
\hline EU & 100 million tons/yr & {$[12]$} \\
\hline US & 0.615 pounds/cap/day & {$[13]$} \\
& 34.69 million tons/yr & {$[14]$} \\
& $31 \%$ of food supplied & {$[7]$} \\
\hline UK & 8.3 million tons/yr & {$[16]$} \\
\hline
\end{tabular}

Previous studies have reported that most of the food wastage has occurred in the consumption stage means that a big portion of food wastage is attributed to consumers or households [4,7]. However, to date, there are not many studies about food waste conducted in Indonesia, in particular at the household level. A study conducted by [17] based on [4] data, reports that through the scenario of world food waste reduction by 25 percent, and then it will result in an increase of rice available for consumption by $4.1 \mathrm{~kg} / \mathrm{capita} /$ year and $2.5 \mathrm{~kg} / \mathrm{capita} / \mathrm{year}$ for Indonesian and world's population, respectively. This scenario provided information that reducing food waste will have a positive impact on food availability, and there is an opportunity to reduce food waste as shown in Table 1. But, for the case of Indonesia, there is a need to provide information about what types of food are most wasted by households, and particularly for rice as the staple food for the majority of Indonesians, we need to know the level of rice waste. This study was carried out to answer those questions.

\section{Research Methods}

\subsection{Location, Sample and Data Collection}

The study was conducted purposively in Sleman and Bantul regencies of Yogyakarta, Indonesia. A total of 122 households typified by single-family dwellings in rural areas were involved in the study after being selected randomly from 3 villages, namely Margodadi and Margoluwih (Sleman) and Srimulyo (Bantul). The respondents of each selected household met pre-specified criteria of having responsibility for the majority of households' food shopping as well as food preparation. The survey was conducted door to door and participants were interviewed by using a set of structured questionnaires. It included 3 consecutive mornings visit by our surveyors' team members to collect and to weigh daily rice waste generated by each household. At the end of the survey, we provided a small monetary incentive to all respondents. 


\subsection{Data Analysis}

\subsubsection{Identifying level of food waste based on food categories}

In the structured questionnaire, respondents were asked to report the average level of food waste for several categories of food, on weekly basis, namely rice, vegetables, fruits, meat, fish, cake, and beverages. The level of food waste consists of 5 that were i) food waste very small (approaching zero), ii) less than $10 \%$, iii) 10 to $25 \%$, iv) 26 to $50 \%$, and v) more than $50 \%$. The data was then analyzed descriptively by calculating the percentage of households for each category of food and each level of food waste.

\subsubsection{Measuring the amount of rice waste and correlation between amount of rice waste and households' size}

The amount of rice waste for each household was obtained through 3 consecutive daily visits door-to-door by weighing all rice (nasi) leftovers collected each morning from all samples of households. To convert cooked rice (nasi) to un-cooked rice (beras), the factor of conversion of 0.38 was used [18].

In addition, many studies reported that food waste level have often been linked with household size. The correlation test between household rice waste levels and household size was employed. The equation of the test is as follows [19]:

$$
r=\frac{n \sum x y-\left(\sum x\right)\left(\sum y\right)}{\sqrt{\left[n \sum x^{2}-\left(\sum x\right)^{2}\right]\left[n \sum y^{2}-\left(\sum y\right)^{2}\right]}}
$$

Description,

$\mathrm{r} \quad$ : coefficient of correlation

$\mathrm{x} \quad$ : household rice waste $(\mathrm{kg} / \mathrm{day})$ and per capita rice waste $(\mathrm{kg} / \mathrm{day} / \mathrm{per}$ capita)

y : household size (persons)

Household rice waste was hypothesized positively correlated with household size, while on the contrary; per capita rice waste was hypothesized to be negatively correlated.

\section{Results and Discussion}

The households typified by single-family dwellings in rural areas of the region of Yogyakarta, Indonesia were involved in the study. Most of the interviewed respondents were female (99\%) and the average age and education levels were 46.5 years old and 10 years of schooling, respectively. This described that on average the respondents were women in the productive age category and held a quite good education level as 10 years of schooling are equivalent to the $1^{\text {st }}$ grade of senior high school. The housewife was typically taken responsibility for households' food preparation so that they suited more than the head of households to answer the questionnaire related to the food waste generated by households. Respondents also reported an average household size of 3.6 people, with an average income per year of IDR 4,212,680,-. The income contributed by farm income was around $22 \%$ as the households involved in this study were mixed between farm and nonfarm households. 
Table 1. Respondents' and Households' Demographics

\begin{tabular}{|l|r|}
\hline Respondents (N=122) & Value \\
\hline Female (\%) & 99.18 \\
\hline Age (years old) & 46.5 \\
\hline Education level (yrs) & 10 \\
\hline Households Characteristics : & 3.6 \\
\hline Family size (persons) & 21.99 \\
\hline Family income (IDR/yr) & \\
\hline Farm income contribution (\%) & 11.96 \\
\hline Occupation (\%) & 11.51 \\
\hline Farmer & 7.45 \\
\hline Employees & 4.29 \\
\hline Self-employed & 2.03 \\
\hline Civil servant & 51.47 \\
\hline Artisan/masonry & 11.29 \\
\hline Housewife & \\
\hline Other &
\end{tabular}

\subsection{The level of food waste generated based on food categories}

In this analysis, food waste is identified based on several main food categories that are commonly consumed by households, namely rice, vegetables, meat, fish, fruit, beverages, and cake. As the main staple food for the majority of Indonesian households, rice is selfcategorized and will be analysed further in terms of its amount of food waste. Meanwhile, the other categories, such as vegetables, fruits, beverages, cakes, fish, and meats do not differentiate each of its components and are reported globally as a whole of each category.

To identify the level of food waste generated by households, the participants were asked to indicate the percentage of each category of food they generally waste. Fig. 1 depicts the distribution of respondents reporting the level of food waste generated by their households for each category of food. As shown in Fig. 1, the green (vertical line) bar indicates the lowest level of food waste as it equals almost $0 \%$; the blue (horizontal line) bar indicates the low level of food waste (less than 10\%); the orange (dotted) bar indicates $10-25 \%$ of food waste; red (solid) bar indicates $26-50 \%$ food waste level; and the black (solid) bar indicates a high level of food waste (more than 50\%). Rice and vegetables are the main categories of food wasted by households. However, it can be recognized that between these two categories there are significant differences since a higher percentage of the level of food waste for rice compared to vegetables reported for the category of " $<10 \%$ " and " 10 $25 \%$ ", while a higher percentage of vegetables recorded for zero waste category. It is also important to note that the level of food waste reported by participants only occurred at home. Yet, it did not record food waste generated by a member of households at restaurants, canteen, ceremonial parties, and so on.

As for rice, more than half of respondents declared that her/his households wasted less than $10 \%$ of cooked rice, while another $26.23 \%$ of respondents reported that their households wasted a $26-50 \%$ portion of the served rice in the home. As for vegetables, more than half of the participants reported that the level of food waste for vegetables is so small. However, there are $9 \%$ and $37.7 \%$ of households wasted $10-25 \%$ and less than $10 \%$ of vegetables, respectively. This result is quite different from [20] who reported that bread and dairy products were the types of food most wasted by Dutch households, while rice and vegetables ranked in $10^{\text {th }}$ and $3^{\text {rd }}$, respectively. Nevertheless, from a deeper point of view, the result is in line with this result of the study, which main staple food comes as the most 
category of food wasted by households as bread could be categorized as a staple food for Dutch households [21]. In addition to that, the majority of rural Indonesian households seldom consume dairy products (such as butter, cheese, yogurt, etc.). The other study, $[22,23]$, reported that fresh fruits and vegetables showed a high percentage of prevalence of food waste by category, in which banana, apple, and tomato counted the largest wasted mass [24].

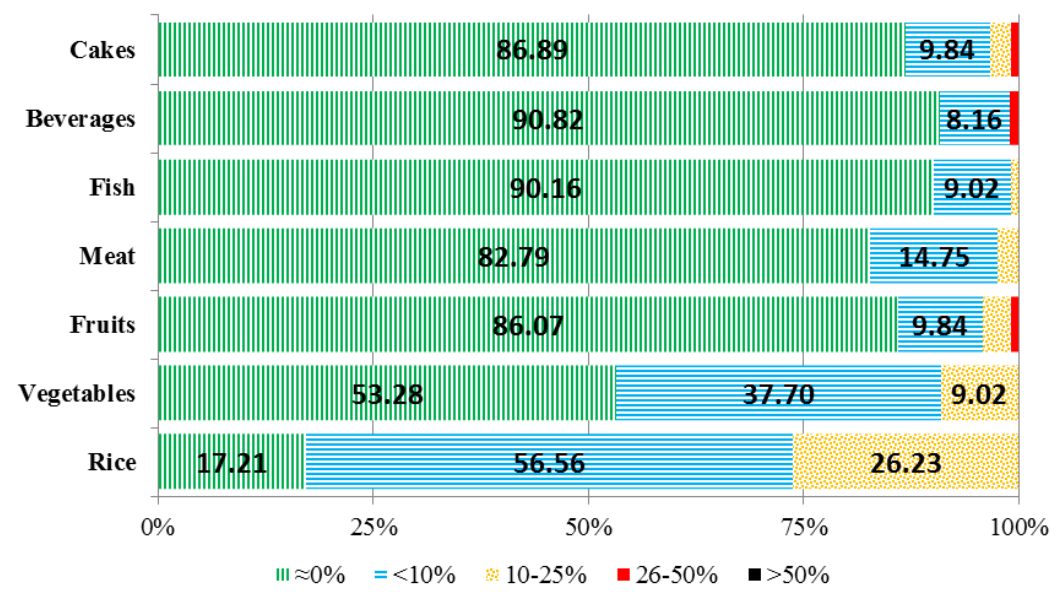

Fig. 1. The level of food waste generated based on food categories

\subsection{Quantifying rice waste by households}

Fig. 2 exhibits the diversity of per household rice waste generated among the surveyed households, which is ranked from the highest average daily rice waste production to the lowest. This graph shows that rice waste generated among households varies largely in the sample. It provides information related to persistent variability and evidence of no clusters of rice waste production in the households. Further research aimed to understand the source of this variability is needed to effectively formulate food waste reduction policies and programs.

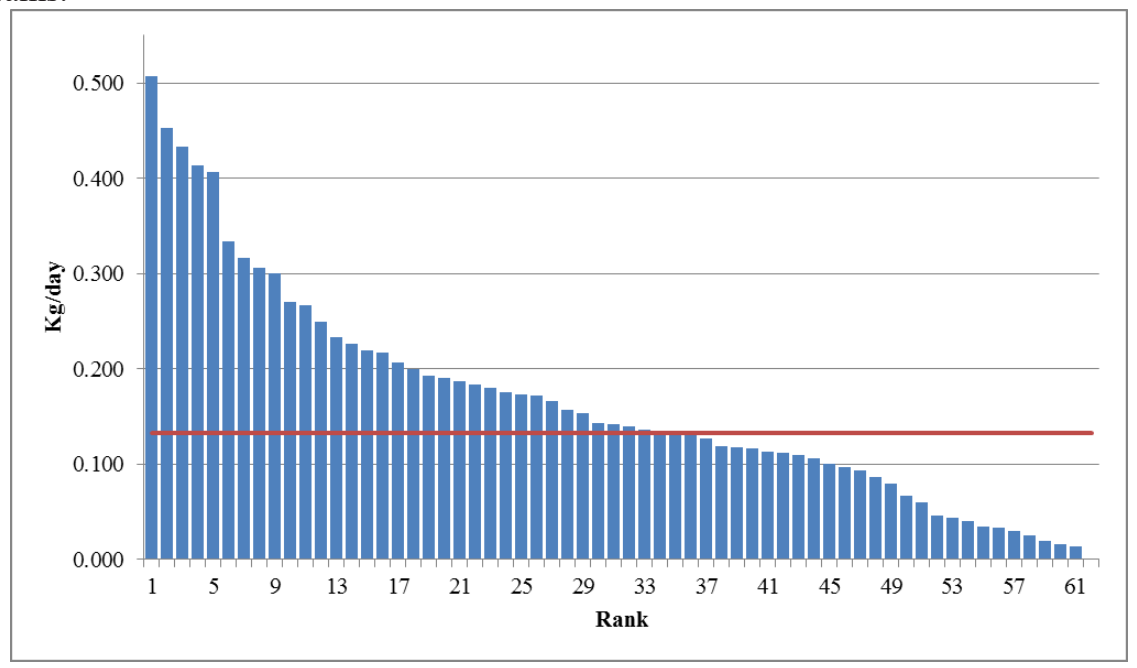

Fig. 2. Per household rice waste organized by rank 
Table 2 reports that on average, households put out $0.133 \mathrm{~kg}$ of rice waste (nasi) per day. This number equals $0.039 \mathrm{~kg} /$ capita per day. It is also important to report that on three days of the survey, on average, the households were quite consistently producing food waste around the range of 0.128 to $0.137 \mathrm{~kg}$ /day. The average rice waste of $0.133 \mathrm{~kg} /$ day per household is roughly equivalent to $0.051 \mathrm{~kg} /$ day of rice (beras $\sim$ uncooked rice) per household. Thus, by comparing the amount of rice waste to the average consumption of rice, on the same period basis, the percentage level of food waste (rice waste) is around 8.7 or it equals $5.1 \mathrm{~kg} / \mathrm{capita} /$ year. Once again, it is important to note that this amount of food waste is only considering rice waste being produced when household members were at home and did not count rice waste occurring outside the home (restaurants, café, canteen, ceremonial parties, etc.). As a comparison, [4] reported that in South/Southeast Asia per capita food wasted by consumers was only $6-11 \mathrm{~kg} / \mathrm{capita} /$ year. Meanwhile, on average per capita rice wasted per year by Dutch people was only $0.9 \mathrm{~kg}$, but bread as their main food counted around $9.2 \mathrm{~kg} / \mathrm{capita} /$ year thrown away as garbage [20].

Table 2. Households' rice consumption and waste

\begin{tabular}{|l|c|c|}
\hline Items & Unit & Value \\
\hline Food waste (cooked rice being wasted) & & \\
\hline Day 1 & $\mathrm{Kg} /$ day & 0.133 \\
\hline Day 2 & $\mathrm{Kg} /$ day & 0.128 \\
\hline Day 3 & $\mathrm{Kg} / \mathrm{day}$ & 0.137 \\
\hline Average & $\mathrm{Kg} / \mathrm{day}$ & $\mathbf{0 . 1 3 3}$ \\
\hline \multirow{2}{*}{ Average rice consumption (uncooked rice $\sim$ beras) } & $\mathrm{Kg} / \mathrm{month}$ & 17.42 \\
\cline { 2 - 3 } & $\mathrm{Kg} / \mathrm{day}$ & 0.58 \\
\hline Average food waste (equivalent to uncooked rice $\sim$ beras)* & $\mathrm{Kg} /$ day & 0.051 \\
\hline Level of food waste & $\mathbf{\%}$ & $\mathbf{8 . 7 1}$ \\
\hline
\end{tabular}

* using 0.38 factor of conversion [18]

The amount of food waste generated by households has been linked to the number of households members. Based on several studies, it has been shown that on a per household basis, households' food waste increases directly with each additional member of the household, but interestingly on a per capita basis, the smaller size of households produce more waste than larger households [16,25-27]. Table 3 confirms that the result of the study is in line with previous findings of other studies.

Table 3. Correlation tests between households' size and amount of food waste

\begin{tabular}{|c|l|c|c|}
\hline \multicolumn{2}{|c|}{} & $\begin{array}{c}\text { Rice waste per } \\
\text { household }\end{array}$ & $\begin{array}{c}\text { Rice waste per } \\
\text { capita }\end{array}$ \\
\hline \multirow{3}{*}{ Household size } & Pearson Correlation & 0.119 & $-0.267^{* *}$ \\
\cline { 2 - 4 } & Sig. (1-tailed) & 0.095 & 0.001 \\
\cline { 2 - 4 } & $\mathrm{N}$ & 122 & 122 \\
\hline
\end{tabular}

** Correlation is significant at the 0.01 level (1-tailed).

\section{Conclusion}

The results of the study reveal that among categories of food, rice and vegetables reported as predominant types of food being wasted by households. The findings also suggest that rice was reported significantly higher than those of vegetables. However, there is no evidence of clusters of rice waste production among households. The estimated waste of rice (nasi) is $0.133 \mathrm{~kg} /$ day or it equals around 8.71 percent of households' average rice consumption. Further research aimed to understand the source of the level of food waste 
variability, as well as household's food waste behavior, are needed to give more insights about the reason behind it and to effectively formulate food waste reduction policy and programs.

\section{References}

1. U. N. D. of E. and S. A. P. Division, World Population Prospects 2019 (2019).

2. Badan Pusat Statistik Indonesia, Proyeksi Penduduk Indonesia Indonesia Population Projection 2010-2035 (2013).

3. D. Qi and B. E. Roe, PLoS One (2016).

4. J. G. et al, Food Agric. Organ. United Nations (2011).

5. FAO, Food Wastage Footprint (2013).

6. M. Gooch, A. Felfel, and N. Marenick, (2010).

7. J. C. Buzby, H. F. Wells, and J. Hyman, in Food Loss United States Sel. Anal. (2014).

8. R. A. Neff, M. L. Spiker, and P. L. Truant, PLoS One (2015).

9. E. Graham-Rowe, D. C. Jessop, and P. Sparks, Resour. Conserv. Recycl. (2014).

10. L. Secondi, L. Principato, and T. Laureti, Food Policy (2015).

11. M. Kummu, H. de Moel, M. Porkka, S. Siebert, O. Varis, and P. J. Ward, Sci. Total Environ. (2012).

12. K. Östergren, Jenny Gustavsson, H. Bos-Brouwers, T. Timmermans, J. Hansen, H. Møller, G. Anderson, C. O’Connor, H. Soethoudt, T. Quested, S. Easteal, A. Politano, C. Bellettato, M. Canali, L. Falasconi, S. Gaiani, M. Vittuari, F. Schneider, G. Moates, K. Waldron, and B. Redlingshöfer, FUSIONS Definitional Framework for Food Waste. Full Report (2014).

13. K. L. Thyberg and D. J. Tonjes, Resour. Conserv. Recycl. (2016).

14. US EPA, 1 (2016).

15. T. E. Quested, A. D. Parry, S. Easteal, and R. Swannell, Nutr. Bull. (2011).

16. T. E. Quested, E. Marsh, D. Stunell, and A. D. Parry, Resour. Conserv. Recycl. (2013).

17. K. Kariyasa and A. Suryana, Anal. Kebijak. Pertan. (2016).

18. Sajiman \& Nurhamidi, 91 (2010).

19. S. Kumar and I. Chong, Int. J. Environ. Res. Public Health 15, (2018).

20. C. van Dooren, O. Janmaat, J. Snoek, and M. Schrijnen, Waste Manag. (2019).

21. M. Geurts, A. M. van Bakel, C. T. M. van Rossum, E. de Boer, and M. C. Ocké, Natl. Inst. Public Heal. Environ. (2017).

22. V. Mijares, J. Alcivar, and C. Palacios, Curr. Dev. Nutr. (2020).

23. Z. Conrad, M. T. Niles, D. A. Neher, E. D. Roy, N. E. Tichenor, and L. Jahns, PLoS One (2018).

24. L. Mattsson, H. Williams, and J. Berghel, Resour. Conserv. Recycl. (2018).

25. J. Jörissen, C. Priefer, and K. R. Bräutigam, Sustain. (2015).

26. K. Parizeau, M. von Massow, and R. Martin, Waste Manag. (2015).

27. H. K. Koivupuro, H. Hartikainen, K. Silvennoinen, J. M. Katajajuuri, N. Heikintalo, A. Reinikainen, and L. Jalkanen, Int. J. Consum. Stud. (2012). 